\title{
HISTORISCH OVERZICHT VAN DE SPOORWEGEN IN WEST-AFRIKA
}

\author{
Jan VAN CRIEKINGE \\ NCOS / De Wereld Morgen \\ Vlasfabriekstraat 11 \\ 1060 Brussel
}

ONDERZOEKSVELD : koloniale geschiedenis, ontwikkeling van de spoorwegen in Afrika, Noord-Zuid-relaties.

\section{SUMMARY}

\section{HISTORICAL SURVEY OF THE RAILWAY DEVELOPMENT IN WEST AFRICA}

The present day railway system in West Africa is the result of the transportpolicy developed by the colonial powers (France, Great Britain and Germany) at the end of the 19th century.It is remarkable that no network of railways, like in Southern Africa, was brought about. The colonial railways in West Africa were built by the State or by a joint-stock company within the borders of one colony to export the raw materials from the production centres to the harbours. Nevertheless railways were built for more than economical grounds only, in West Africa they had to accomplish a strategic and military role by "opening Africa for the European civilization". Hargreaves calls railways the "heralds of new imperialism" and Baumgart speaks of the own dynamics of the railways, to push the European colonial powers further into Africa... The construction of a railway needed a very high capital investment and the European capitalists wouldn't like to take risks in areas that were not yet "pacified". It is remarkable how many projects to build a Transcontinental railway right across the Sahara desert largely remained on paper. Precisely because such plans did not materialize, however, the motive force they 
provided to such imperialist actions as political-territorial annexations can be traced all the more clearly.

The French built the first railway in West Africa, the Dakar - St-Louis line (Senegal), between 1879 and 1885. This line stimulated the production of ground-nuts, although the French colonial-military lobby has had other motives. The real motivation became very clear at the construction of the Kayes - Bamako railway. Great difficulties needed the military occupation of the region and the violent recruitment of thousands of black labourers, all over the region. The same problems transformed the building of the KayesDakar line into a real hell. Afterwards the Siné Saloum region has been through a "agricultural revolution", when the local ground-nuts-producers have been able to produce for foreign markets. The first British railways were built in Sierra Leone and the Gold Coast-colony (Ghana). In Nigeria railway construction stimulated the growth of Lagos as an harbour and administrative centre. Lugard had plans for the unification of Nigeria by railways. The old Hausa town of Kano flourished after the opening of the Northern Railway, for other towns a period of decline had begun. Harbour cities and interior railwayheads caused an influx of population from periphery regions, the phenomenon is called "port concentration". Also the imperial Germany built a few railwaylines in their former colony Togo, to avoid the traffic flow off to the British railways. It's quite remarkable that the harbours at the Gulf of Guinea-coast developed much later than the harbours of Senegal and Sierra Leone.

After the First World War only a few new railways were constructed, the revenues remained very low, so the (colonial) state had to take over many lines. The competition between railways and roadtransport demonstrated the first time in Nigeria, it was the beginning of the decline of railways as the most important transportsystems in West Africa. Only multinational companies built specific railways for the export of minerals (iron, ore and bauxite) after the Second World War, and the French completed the Abidjan - Ouagadougou railway (1956).

The consequences of railway construction in West Africa on economic, demographic and social sphere were not so far-reaching as in Southern Africa, but the labour migration and the first labour unions of railwaymen 
who organized strikes in Senegal and the Ivory Coast mentioned the changing social situation.

The bibliography of the West African railways contains very useful studies about the financial policy of the railway companies and the governments, but only a few railways were already studied by economic historians.

KEY WORDS : bibliographical survey, colonial history, economic and demographic consequences, railway development, West Africa

\section{INLEIDING}

Het huidige transportsysteem van West-Afrika en dan vooral de spoorwegen, zijn het resultaat van het transportpatroon zoals dat in de koloniale periode werd uitgebouwd. Het valt daarbij op dat in West-Afrika, in tegenstelling tot Zuidelijk Afrika, geen geïntegreerd spoorwegnet tot stand kwam. Slechts twee spoorlijnen, nl. de lijn Dakar-Bamako en de lijn Abidjan- Ouagadougou, overschrijden staatsgrenzen. Alle andere spoorwegen lopen vanuit het binnenland naar een kusthaven in hetzelfde land. Het transportsysteem is dus duidelijk afgestemd op de export van grondstoffen naar gebieden buiten West-Afrika, terwijl de onderlinge handel meestal zeer beperkt blijft.

Vanaf $1870 \mathrm{kwamen}$ delen van West-Afrika steeds meer onder Europese kontrole en werden ingeschakeld in de exportekonomie. Om de 'mise en valeur' van de nieuw verworven gebieden mogelijk te maken, diende het transportsysteem aangepast te worden aan de technologische ontwikkeling van de late 19de eeuw: de spoorweg had de transportrevolutie in Europa mogelijk gemaakt en zou nu ook de ekonomie van West-Afrika veranderen (1).

Hargreaves noemt de spoorwegen "heralds of new imperialism in West Africa", spoorwegen hadden niet in de eerste plaats een ekonomische funktie, maar werden beschouwd als de ideale instrumenten om de 'pénétration pacifique' mogelijk te maken (2). Volgens de imperialisme-theorie van Baumgart werden spoorwegen niet alleen gebruikt als instrumenten van het imperialisme - het onder kontrole brengen van de binnenlanden - maar waren de spoorwegen zélf een motivering voor de Europese expansie in de binnenlan- 


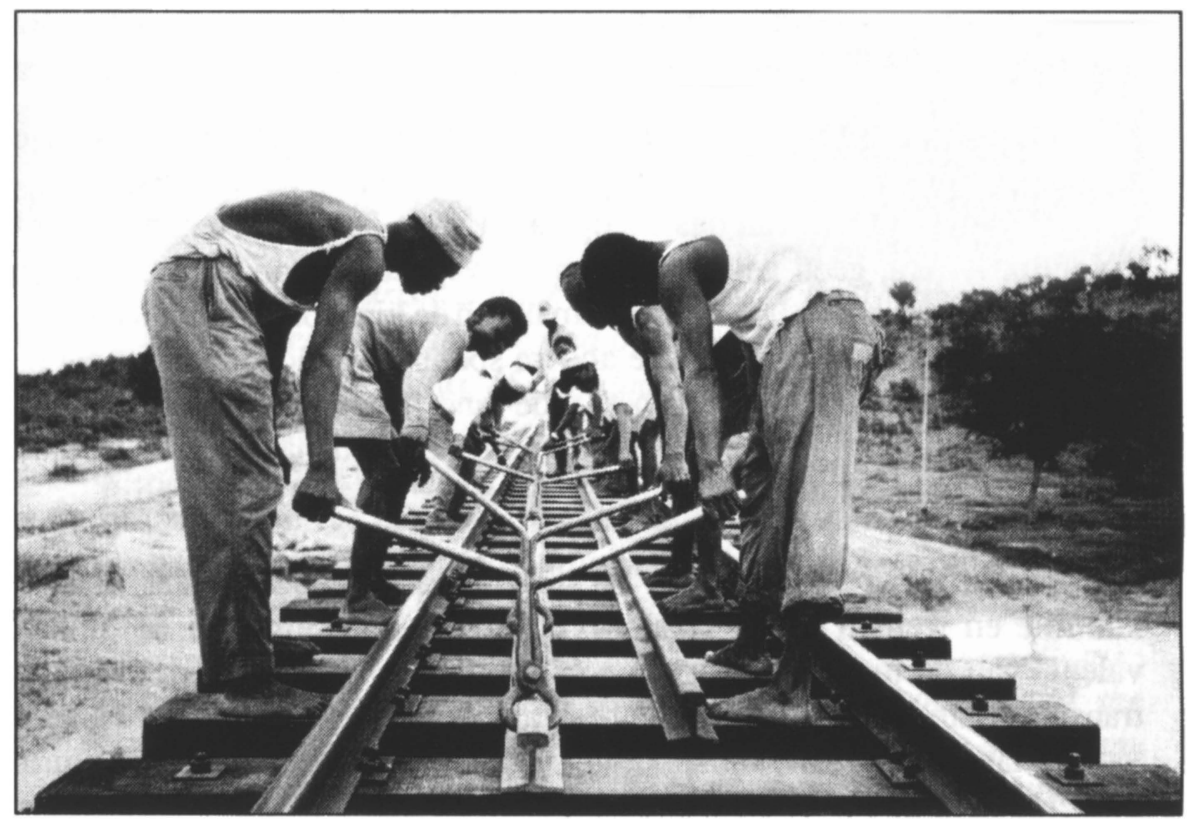

De aanleg van een spoorweg in Nigeria in 1961.

Foto: J. Moss (Wereldbank) 
den. De aanleg van een spoorlijn vereiste immers een zware kapitaalinvestering, die beschermd diende te worden (3).

De plannenmakers van de eerste spoorwegen drongen er bij hun regering dan ook op aan om die gebieden onder politieke kontrole te brengen of te 'pacificeren', en spoorwegen konden natuurlijk daar toe bijdragen... Wrigley stelt zelfs: "More than anything else, it was the exigencies of railway-building that had brought the European states into Africa" (4).

Dit artikel wil een historisch overzicht bieden van de spoorwegontwikkeling in West-Afrika, van de aanleg van de eerste lijnen als instrumenten van koloniale penetratie, tot de bouw van ertsspoorwegen door multinationale ondernemingen na de Tweede Wereldoorlog.Daarbij wordt ook aandacht besteed aan de ekonomische,demografische en sociale gevolgen van de spoorwegaanleg.

Tot slot volgt nog een aantal bibliografische opmerkingen over het behandelde onderwerp $(*)$.

\section{DE EERSTE WESTAFRIKAANSE SPOORWEGEN (1875-1914)}

In de jaren zeventig van de 19de eeuw kwamen de eerste transkontinentale spoorwegen tot stand in Noord-Amerika, later volgden ook Australië en Rusland. De schijnbaar onbeperkte mogelijkheden van de spoorwegtechniek zouden ook het 'donkere hart' van Afrika kunnen 'openen voor de beschaving'; vooral in Frankrijk, dat door de nederlaag van 1871 in zijn nationale trots was gekwetst,ontstond een echte 'railway fever'. In kringen van militairen en aardrijkskundige genootschappen begon men te denken aan de aanleg van een 'Transsahara-spoorweg', die de Noordafrikaanse Franse bezittingen zou verbinden met de bovenloop van de Niger of zelfs de Golf van Guinée (5). Helemaal nieuw waren deze plannen niet, schrijvers als Jules Verne en Ibsen (Peer Gynt) hadden dit 'lyrisme ferroviaire' gevoed (6).

Konkreet werd het wel toen in 1875 de Franse'ontdekkingsreiziger' Paul Soleillet, samen met minister Freycinet en spoorwegingenieur Duponchel een aktieve campagne begonneri um een Transsaharalijn aan te leggen. Men zou

* De volledige bibliografie, ingedeeld in geografische rubrieken, bevat 317 referenties. Geïnteresseerden kunnen een kopie aanvragen bij de auteur. 
alvast beginnen vanuit Senegal om een verbinding met de bovenloop van de Niger tot stand te brengen.

Volgens vele auteurs begint de 'scramble for Africa' juist in 1879 met het uitvoeren van de spoorwegplannen in Senegal: de aanleg van de lijn die St-Louis (aan de monding van de Senegalrivier) zou verbinden met Dakar, de beter gesitueerde exporthaven. De Senegal zou verder moeten worden verbonden met de Niger om de Franse penetratie mogelijk te kunnen maken (7).

De lijn Dakar-St-Louis, die in 1885 werd geopend, doorkruiste een belangrijk aardnotenproduktiegebied, zodat de spoorlijn ook ekonomisch interessant zou kunnen worden. Toch was de rendabiliteit niet prioritair, dat bleek duidelijk bij de aanleg van de spoorlijn van Kayes (aan de Senegal) naar Bamako en Koulikoro (Niger) (1882-1904). Er dienden eerst forten te worden gebouwd om de regio te 'pacificeren' en naarmate de werken vorderden werd alles onder militair bestuur gebracht, wat de gewelddadige rekrutering van arbeiders vergemakkelijkte. De werken kampten met grote technische problemen en werden een zware financiële dobber voor de Franse staat, daar inkomsten op korte termijn niet te verwachten waren, en privé-maatschappijen dus niet zoveel wilden investeren in risicodragende, kapitaalintensieve ondememingen. De lijn had dan ook in eerste plaats militair-strategisch belang (8).

De uitvoering van de totaal onrealistische Transsahara-spoorwegplannen diende om financiële en politieke redenen opgeschort te worden (0.a. Touareg-opstanden), maar toch bleven in Franse koloniaal-militaire kringen geregeld nieuwe megalomane plannen opduiken tot in 1941 toe; nooit werd er echter iets gerealiseerd.

"The schemes to span the African continent with railways largely remained on paper. Precisely because such plans did not materialize, however, the motive force they provided to such imperialist actions as political-territorial annexations can be traced all the more clearly" (9).

Ondertussen was ook Groot-Brittannië begonnen met de aanleg van spoorwegen in West-Afrika. In Sierra Leone, de oudste Britse kolonie, werd van 1896 tot 1905 de spoorweg van Freetown naar Pendembu gebouwd (in smalspoor, $76 \mathrm{~cm}$ spoorbreedte). Deze staatsondememing had tot doel de 
kolonie en het protektoraat nauwer aan elkaar te binden en terzelfder tijd de ekonomische ontwikkeling te stimuleren. Dit laatste lukte behoorlijk, zodat al spoedig de lijn werd verlengd tot aan de Liberiaanse grens, een gebied rijk aan oliepalmen (10).

In de Gold Coast (nu Ghana) werd een spoorlijn aangelegd van de haven van Sekondi naar Kumasi (274 km), de hoofdstad van het Ashanti-rijk, dat door de Britten op brutale wijze was verslagen. De lijn had, net zoals de Franse lijnen, vooral een militaire bestaansreden en heeft fundamenteel bijgedragen tot de totale ondergang van de Ashanti-staat,terwijl de export van goud en wat later ook van cacao een grote stimulans kreeg.

De spoorlijn Lagos-Ibadan in Nigeria (1896-1900) veroorzaakte een geweldige groei van Lagos als stad, exporthaven en administratief centrum, zeker nadat besloten werd de lijn verder door te trekken tot de Noordnigeriaanse hanüelsmetropool Kano. Volgens het Lugard-plan zouden spoorwegen in Nigeria een essentiële rol spelen in de eenmaking van het land. Noord-Nigeria werd vanaf de voltooiing van de lijn tot Kano (1911), onder impuls van de Hausa-handelaren, een belangrijke aardnotenproducent gericht op de export, terwijl andere streken, die minder gunstig lagen t.o.v. de spoorweg in de ekonomische periferie terecht kwamen (11).

Vooral tussen 1900 en 1914 werden in bijna alle Westafrikaanse koloniën spoorwegen aangelegd, meestal met de bedoeling om bepaalde ekonomisch interessante gebieden te verbinden met een gunstige exporthaven (12).

Duitse privé-maatschappijen begonnen met de bouw van drie spoorwegen in Togo om de eenmaking van het land te bevorderen, de afhankelijkheid van de Britse kolonie Gold Coast te verminderen, maar in de eerste plaats om de export van landbouwprodukten zoals cacao, katoen en palmolie op grote schaal mogelijk te maken (13).

Gouverneur-generaal E.N. Roume van de A.O.F.-federatie beschouwde de aanleg van spoorwegen als essentieel om de exportekonomie te stimuleren. In Guinée werd de lijn Conakry-Niger aangevat (1900-1914) om de rijke rubbergebieden aan de bovenloop van de Niger te kunnen exploiteren en te voorkomen dat goederen naar de lijn in Sierra Leone zouden afvloeien. Aan de Golf van Guinée kwam de spoorwegontwikkeling wat later op gang. Door 


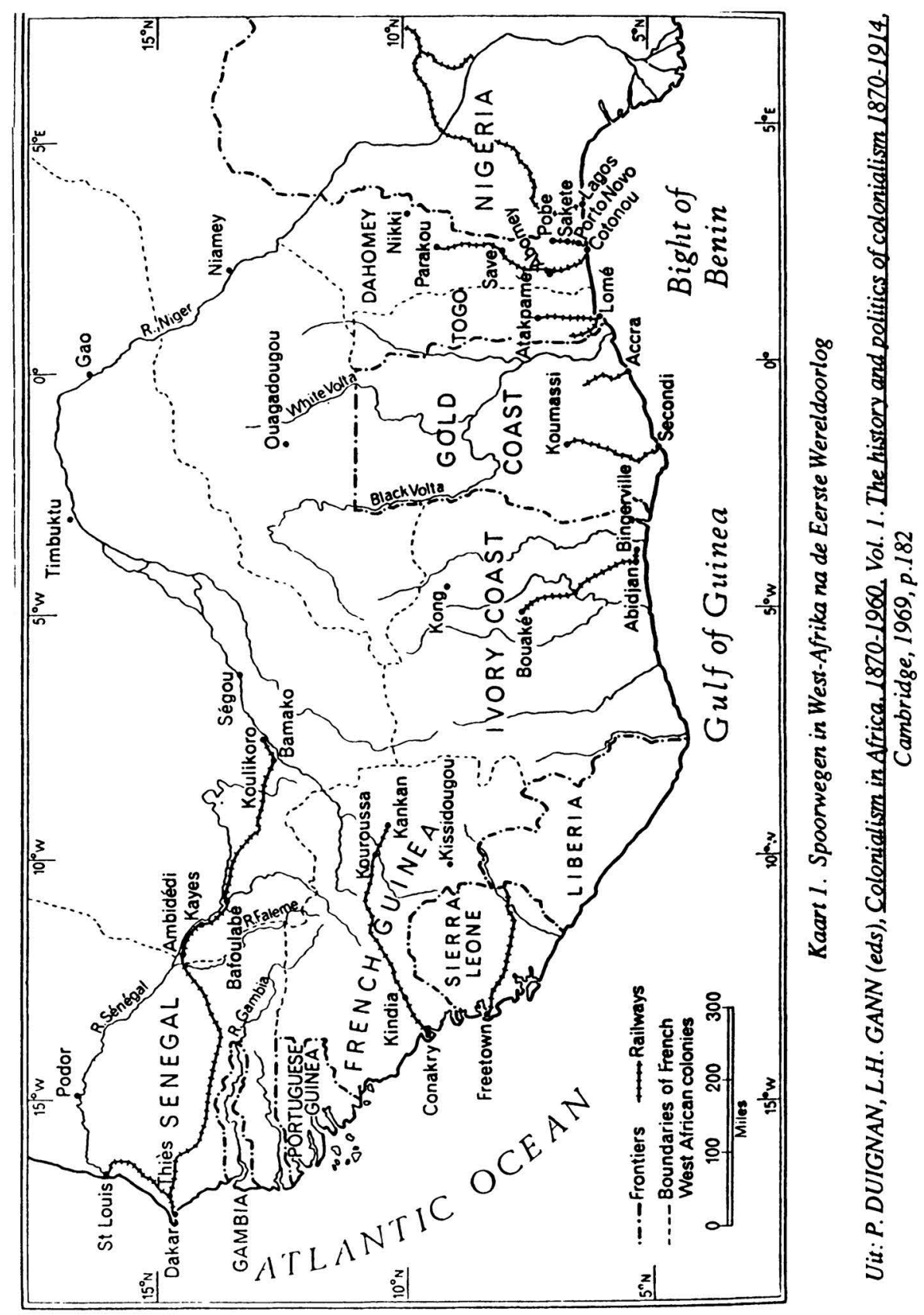


het gebrek aan geschikte natuurlijke havens, kon de aanleg van spoorwegen pas beginnen nadat de exporthavens klaar waren. Zoals in Dahomey,de lijn Cotonou-Savé, (1901) en later Porto-Novo - Pobé (1908); en vooral in Ivoorkust, waar de lijn Abidjan-Bouaké (1904-1912) ook van militair belang was in expedities tegen de Baoule-weerstand (14). De wisselvallige waterstanden van de Senegal-rivier maakten de scheepvaart vaak onmogelijk zodat besloten werd om de spoorweg van Kayes naar Bamako (nu in Mali) rechtstreeks te verbinden met Dakar. Dit $677 \mathrm{~km}$ lange stuk werd in 1907 aangevat, maar pas in 1924, na zeer veel moeilijkheden en massaal gebruik van 'travail forcé', voltooid. Deze lijn loopt door het rijke aardnotengebied van Siné Saloum, dat na 1924 een ware 'landbouwrevolutie ' beleefde, toen de Afrikaanse producenten op de wereldmarkt aangesloten werden (15).

\section{DE SPOORWEGBOUW NA DE EERSTE WERELDOORLOG}

Tijdens de Eerste Wereldoorlog werd de spoorwegbouw grotendeels stilgelegd om alle beschikbare mankracht te kunnen mobiliseren in het leger. $\mathrm{Na}$ de oorlog werd het bestaande basisnet verder aangevuld, maar echt grote, nieuwe plannen of de realisatie van de oorspronkelijke plannen bleven uit. In Nigeria werd de Oostnigeriaanse spoorweg van Port Harcourt via het Udisteenkoolbekken en het Jos-plateau (tin) aangesloten op het eerder gerealiseerde net. Toch was juist Nigeria, door de snelle ontwikkeling van het wegtransport, het eerste land waar de konkurrentie weg-spoor zich manifesteerde. Wegens de zware investeringen en vaak beneden verwachting gebleven opbrengsten, waren vele spoorwegen verlieslatende ondernemingen, die niet zelden door de staat dienden te worden overgenomen. Het wegtransport daarentegen was niet alleen goedkoper (aanleg), maar ook soepeler en kon door kleine privé-maatschappijen worden verzekerd (16).

Er werden evenwel nog enkele spoorwegen aangelegd in ekonomisch gunstige gebieden, zoals de spoorweg van Accra naar Kumasi (Ghana), die doorheen rijke cacaogebieden liep, ook goud- en bauxietmijnen werden in de omgeving ontwikkeld. De ekonomische krisis van de jaren dertig deed de Britse koloniale overheid afzien van het Guggisberg-plan om ook NoordGhana met een spoorweg te verbinden (Northem Territories Railway). De Fransen bouwden nochtans wel verder aan hun spoorwegen: in 1934 werd Bouaké met Bobo Dioulasso (nu in Burkina Faso) verbonden en in 1936 


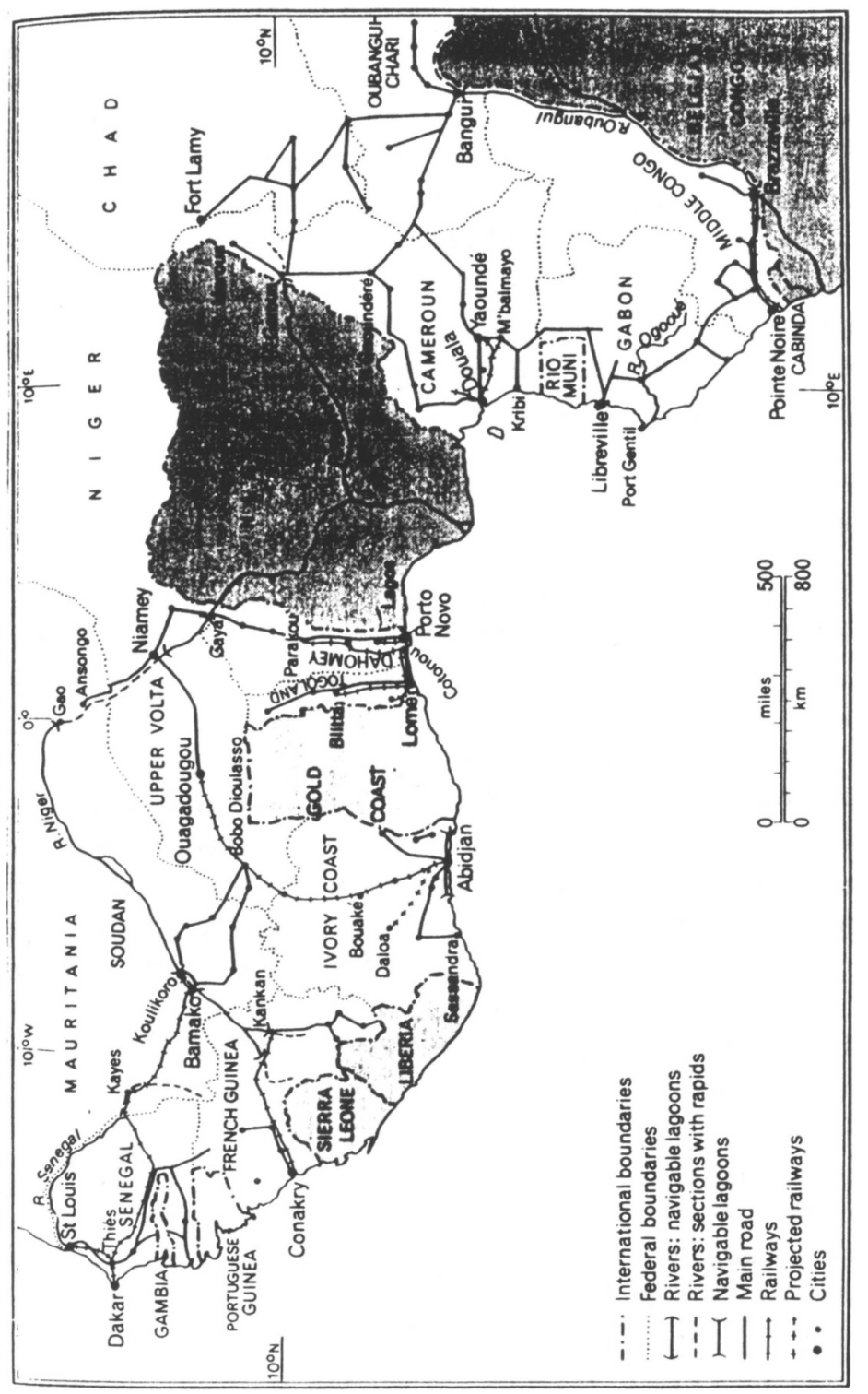

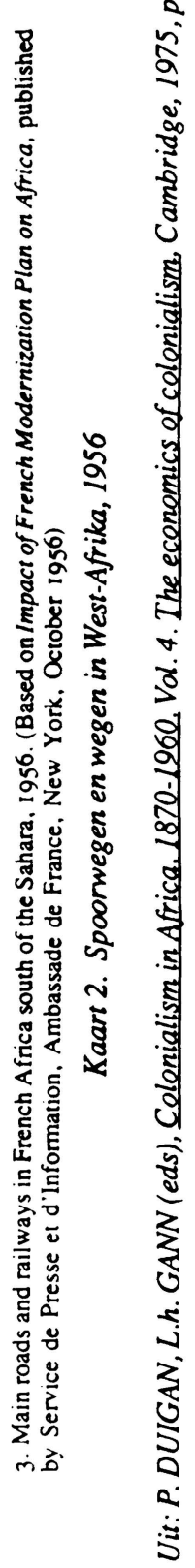


bereikte de Dahomey-lijn zijn (voorlopig) eindpunt Parakou (17). Deze spoorwegen hadden ook een strategische betekenis.

$\mathrm{Na}$ de Tweede Wereldoorlog waren alle investeringen in de transportsektor gericht op het wegvervoer. Wegen hadden nu niet meer alleen een aanvullende funktie ('feeder roads'), maar ontwikkelden tot zelfstandige transportsystemen. De belangrijkste spoorweg die nog tot stand kwam in de koloniale tijd was de lijn Bobo Dioulasso - Ouagadougou (1956), zodat eindelijk het dicht bevolkte Mossi-plateau een spoorverbinding met Abidjan had.

In een aantal Westafrikaanse landen werden na de onafhankelijkheid nog ertsspoorwegen gebouwd, die de verbinding moesten verzorgen tussen een mijngebied en een exporthaven. Niet zelden werden deze lijnen aangelegd door de (multinationale) mijnbouwmaatschappijen zelf. Liberia, een land dat tot 1951 geen spoorwegen had, zag zich 'verrijkt' met vier spoorlijnen, die ijzererts naar de havens van Monrovia en Buchanan vervoeren (18). In het buurland Sierra Leone daarentegen werden alle spoorwegen gesloten omdat ze niet rendabel waren.Sinds 1982 werd de Marampa Mineral Railway (84 km, Marampa-ijzermijn naar Pepel-haven) evenwel terug in gebruik genomen.

Om bauxietmijnen te kunnen exploiteren werden in Guinée ook enkele nieuwe lijnen aangelegd met de hulp van de Wereldbank, de Sovjet-Unie en Japan. Er zouden zelfs plannen bestaan om een nieuwe lijn, dwars door het land, naar de Nimba-bergen (ijzererts) aan te leggen, terwijl op Liberiaans grondgebied reeds de veel kortere verbinding met Buchanan bestaat (19). Tenslotte kwam ook in Mauretanië een $670 \mathrm{~km}$ lange ijzerertsspoorweg gereed, dwars door de woestijn, naar de nieuwe haven van Nouadhibou.

Ondanks die enkele recente lijnen, kan men stellen dat het huidige Westafrikaanse spoorwegnet nog grotendeels bestaat uit het koloniale net van rond 1914.

\section{DE GEVOLGEN}

Dat de spoorwegen een grote impakt gehad hebben op de ontwikkeling van West-Afrika is een stelling die door alle auteurs wordt gedeeld. 
Vooreerst waren er de ekonomische gevolgen: de aanleg van spoorwegen veroorzaakte vaak de ondergang van de Afrikaanse handelssystemen. De ekonomische ruimte werd vooral gericht op de exporthavens aan de kust. Intussen vervielen de binnenlanden tot periferie (20).

De havens waarop een spoorweg aansloot, en de inlandse termini werden bloeiende centra, terwijl oudere centra die niet aan een spoorweg lagen, steeds meer verlaten werden (verschijnsel van port-concentration) (21). In grote delen van West-Afrika werd zelfs nooit een spoorweg aangelegd: Niger, Noord-Mali, Noord-Togo, Noord-Ghana, Guinée Bissau,...

Nauw hiermee in verband staat de demografische evolutie: enkele steden groeiden zeer snel dankzij de spoorweg (v.b. Lagos). Bijna overal ontstonden nieuwe nederzettingen en bevolkingskoncentraties langs de spoorlijn en vervielen oude centra, zeer duidelijk was dit verschijnsel in de Futa Djalon (Guiné) en in Ivoorkust (22).

De aanleg van spoorwegen in de koloniale tijd was onmogelijk geweest zonder de massale inzet van goedkope, zwarte arbeidskrachten. De rekrutering verliep zelden vreedzaam en in bijna alle kolonies werd in min of meerdere mate gebruik gemaakt van gedwongen arbeidskrachten bij grote openbare werken zoals spoorwegen. In dun bevolkte streken werden arbeiders over grote afstanden aangevoerd; ekonomisch weinig waardevolle gebieden (volgens de mening van de kolonisator), dienden als arbeidsreservoir te fungeren. Bij de aanleg van de spoorweg Kayes-Bamako (1904) werd ieder distrikt van de federatie verplicht een minimum aantal arbeiders te leveren, omdat de Bambara-bevolking de druk alleen niet meer kon dragen. In totaal werden zelfs 22.000 arbeiders uit Opper-Volta (Mossi) gerekruteerd (23). Spoorwegen hebben de arbeidsmigratie vanuit de armere binnenlanden naar de rijkere kustgebieden in de hand gewerkt.

De koncentratie van arbeiders in dienst van de spoorwegmaatschappijen deed al vlug een zeker bewustzijn groeien, dat zich manifesteerde in sociale onrust of stakingen. Reeds in 1904 ging het administratief spoorwegpersoneel van Lagos in staking, maar vooral na de Eerste Wereldoorlog kwamen overal in West-Afrika stakingen van spoorwegarbeiders voor. De felle inflatie en/of niet uitbetalen van de beloofde oorlogspremie waren hiervoor verantwoorde- 
lijk: In de jaren dertig en veertig deden zich nog radikale spoorstakingen voor in Senegal en Ivoorkust (24). In West-Afrika, met relatief weinig industriearbeiders, zijn de spoorwegpersoneelsleden de belangrijkste vakbondsmilitanten gebleven.

\section{BIBLIOGRAFISCHE OPMERKINGEN}

De belangrijke en ingrijpende rol die spoorwegen in de koloniale en post-koloniale ontwikkeling van West-Afrika hebben gespeeld, kan moeilijk worden ontkend.

Er bestaat dan ook een uitgebreide literatuur over het onderwerp. Vooral in de koloniale periode was de belangstelling erg groot, vele publikaties waren bedoeld als propaganda voor de aanleg van nieuwe,gedurfde, en niet zelden nooit gerealiseerde spoorwegen, zoals de Franse 'Transsaharien' (25). In geografische tijdschriften werd veel aandacht besteed aan spoorwegen als ideaal middel om nieuwe gebieden te 'openen' en in te schakelen in de exportekonomie. Niet weinig werken zijn met zeer apologetische bedoelingen geschreven: de spoorweg als 'beschavingsbrenger' in Afrika.

Een klassiek en degelijk overzichtswerk uit de koloniale tijd is het werk van Baltzer uit 1916 (26). Na de dekolonisatie werd op een meer kritische manier geschreven over het transportsysteem dat de kolonisatoren in Afrika hadden achtergelaten en over de gevolgen voor de onafhankelijke landen (27).

Interessante informatie over spoorwegontwikkeling in West-Afrika in het algemeen is te vinden in de studies van de Britse ekonoom-geograaf Harrison Church (28). De transportproblemen van de Westafrikaanse 'land-locked countries' komen aan bod in de bijdrage van Cervenka (29) ; terwijl de transportproblematiek in een ruimere ekonomische kontekst is behandeld in de studies van Clower (e.a.) voor Liberia (30) en Gould voor Ghana (31). De konkurrentie tussen spoor- en wegvervoer in Nigeria is beschreven door Ijewere (32). En over de spoorweg Abidjan - Ouagadougou werd door Lacognata een grondige geografische studie gemaakt (33).

Toch is het merkwaardig dat er weinig, grondige historische studies over de Westafrikaanse spoorwegen zijn verschenen. Alleen de lijn Conakry - Kankan 
(Guinée) is door Mangolte vrij grondig bestudeerd (34), daarenboven heeft een aantal Nigeriaanse historici (o.a. Omosini en Oyemakinde) zich bezig gehouden met de spoorwegen in de Britse koloniale politiek in Nigeria (35). De imperialistische rol van de spoorwegen komt vooral tot uiting in de werken van Roberts en Baumgart (36).

Verder hebben ekonomische historici zich nogal gericht op de financiële kant van de spoorwegen; dat hoeft niet te verwonderen daar spoorwegen de grootste kapitaalinvesteringen in Afrika vertegenwoordigden. Beroemd, en nog erg bruikbaar is het standaardwerk van Frankel uit 1938 (37).

Algemene beschouwingen over de Franse kapitaalinvesteringen in de AOFfederatie kan men terugvinden in de studies van Coquery-Vidrovitch en Brunschwig (38). Cox-George bestudeerde de financiering van spoorwegen in Ghana. Lakroum heeft het financiële beleid van de lijn Dakar - St-Louis doorgelicht (39).

De sociale gevolgen en de veranderingen die spoorwegen hebben veroorzaakt bleven lange tijd verwaarloosd. Hopkins schrijft in 1973 nog: "... It is surprising that economic historians have conducted so little research into the subject" (40). Ondertussen is er wel een aantal studies verschenen, die de leemte gedeeltelijk moeten opvullen, zoals de dissertatie van Pheffer over de sociale veranderingen t.g.v. de spoorwegen in Senegal (41) of de studies van Semi-Bi Zan voor Ivoorkust (42).

Ook aan de spoorwegarbeiders, de strategie van arbeidsreservoirs en aan stakingen werd de laatste jaren meer aandacht besteed door historici: voorbeelden zijn de studie van Cocou voor Dahomey en Cordell voor Burkina Faso (43). Stakingen van spoorwegarbeiders in Senegal en Sierra Leone zijn beschreven door Mbengue, Suret- Canale, Iba der Thiam en Wyse (44).

\section{BESLUIT}

Spoorwegen hebben in West-Afrika een niet geringe rol gespeeld bij de Europese kolonisatie van de uitgestrekte binnenlanden. Strategische overwegingen wogen vaak zwaarder door dan zuiver ekonomische motieven. Opvallend hierbij is het grote aantal nooit gerealiseerde spoorwegplannen om een lijn dwars doorheen de Sahara aan te leggen. In Frankrijk was een 
Toch hebben de spoorwegen de ekonomische,demografische en sociale situatie grondig beïnvloed,zonder nochtans een zo diepgaande verandering teweeg te brengen als het spoorwegnet van Zuidelijk Afrika.De relatieve afwezigheid van interessante mijnbouwstreken,die de ekonomische leefbaarheid van veel lijnen moest mogelijk maken,leidde tot minder investeringen in de Westafrikaanse spoorwegen. Daarenboven liet de konkurrentie van het wegtransport zich al vroeg voelen,vooral in het volkrijkste land, Nigeria. Grotendeels is het huidige spoorwegnet dan ook nog gebaseerd op het koloniale net van 1914. Een aantal lijnen werd reeds bestudeerd,maar andere wachten nog op behandeling.

Men kan zich afvragen of het aanleggen van enkele nieuwe lijnen- zoals b.v. gebeurde in Gabon en Kameroen-het transportprobleem niet efficiënter zou oplossen,dan het geval is met de toename van het wegtransport over vaak slecht onderhouden wegen met een te lage kapaciteit.

"More than any other innovation, railways symbolised the links between profit and power".

LONSDALE, in: The Cambridge History of Africa, vol.6, 1870-1905, Cambridge, 1985, p.696. 


\section{NOTEN}

(1) A.G.HOPKINS, Aneconomichistory of West Africa, Londen, 1973, p. 156: "The railway, the White Hope of the nineteenth century, was thought to be capable of transforming the economies of West Africa, just as it had those of Europe."

(2) J.D.HARGREAVES, West Africa partitioned. Vol. 1. The loaded pause, 1885-1889. Londen, 1974, p. 15-16.

(3) W.BAUMGART, Imperialism, the idea of British and French colonial expansion, 18801914. Oxford, 1982, 1986 uitg. 4, p. $25-26$.

(4) C.C.WRIGLEY, "Aspects of economic history", The Cambridge History of Africa, vol. 7. 1905-1940, Cambridge, 1986, p. 79: "Railways are uniquely large, expensive and vulnerable pieces of fixed capital, which demand political security over wide areas."

(5) W.BAUMGART, ص., p. 28.

(6) G.N.SANDERSON, "The European partition of Africa: origins, dynamics", The Cambridge History of Africa vol. 6. 1870-1905, Cambridge, 1985, p. 98.

(7) o.a. W.BAUMGART, Q... p. 2 en ook J.D.HARGREAVES, Q.c. p. 30.

(8) H.BRUNSCHWIG, "French exploration and conquest in Africa", L.H. GANN (ed), Colonialism in Africa vol. 1., Cambridge, 1969, p. 137.

C. COQUERY-VIDROVITCH, "French colonization in Africa", L.H. GANN (ed), CelonialisminAfrica, vol. 1., Cambridge, 1969, p. 180. W. BAUMGART, 0.c., p. 29: "That they (railways) generated a dynamism which spread beyond the sphere of transportation is an extra ordinarily important element of the phenomenon of imperialism."

(9) W.BAUMGART, Q... p. 29.

H.BRUNSCHWIG, e.c. p. 138.

De bekendste Transsahara-plannen zijn die van Sébillot uit 1893 en van Roumens uit 1914. Sébillot voorzag een lijn van $2 \mathrm{~m}$ spoorbreedte en "forts mobiles", gepantserde treinen, die met een snelheid van $100 \mathrm{~km} / \mathrm{u}$ van Algiers naar Agades (Niger) zouden rijden.

(10) J.D.HARGREAVES, "Western Africa, 1886-1905", The Cambridge History of Africa, vol. 6. 1870-1905, Cambridge, 1985, p. 272.

(11) D.C.DORWARD, "British West Africa and Liberia", The Cambridge History of Africa, vol. 7. 1905-1940, Cambridge, 1986, p. 407:

"Moreover, railways, dictated by strategic considerations and existing or perceived British marketing opportunities, favoured selected areas while relegating others to the economic periphery." 
J.D.FAGE, Ahistory of West Africa, Cambridge, 1969, p.193 (Economic development in British West Africa).

(12) J.D.HARGREAVES, "Western Africa, 1886-1905", The Cambridge History of Africa vol. 6. 1870-1905, Cambridge, 1985, p. 295: "Economically, the conquest was beginning to show results. Railways designed to channel trade towards the oceanic ports were well advanced in every coastal colony."

(13) H.BRUNSCHWIG, "French exploration and conquest in Africa", L.H. GANN, P. DUIGNAN (eds), Colonialism in Africa, vol. 1., Cambridge, 1969, p. 137.

D.C.DORWARD, "British West Africa and Liberia", (Togoland), The Cambridge History ef Africa, vol. 7. 1905-1940. Cambridge, 1986, p. 419-420.

L.H.GANN, "Economic development in Germany's African empire", L.H.GANN, P. DUIGNAN (eds), Colonialism in Africa, vol. 4., Cambridge, 1975, p. 240.

(14) J.S.HOGENDORN, "Economic initiative and African cash farming", L.H.GANN, (ed), Colonialism in Africa, vol. 4., Cambridge, 1975, p. 295: "... railway construction became the central focus of economic policy between the turn of the century and 1910."

C.W.NEWBURY, The Westem Slave Coast and its rulers, Oxford, 1961, p. 145-146:

"Nous savons quel admirable instrument de pacification ce chemin de fer a été pour la région de Sakété (Dahomey)."

(15) C.COQUERY-VIDROVITCH, "French black Africa, 1905-1940", The Cambridge His!ory of Africa, vol. 7. 1905-1940, Cambridge, 1986, p. 344.

(16) D.C.DORWARD, "British West Africa and Liberia", The Cambridge History of Africa, vol. 7. 1905-1940, Cambridge, 1986, p. 430-435.

(17) H.L.VAN DER LAAN, "Modem inland transport and the European trading firms in colonial West Africa", Cahiers d'Etudes africaines, 84, xxi-4, p.555

(18) R.J.HARRISON CHURCH, West Africa: environment and policies New York, 1976, p. 56.

De spoorlijn van de ijzermijn van Mt.Nimba naar de haven van Buchanan gaat dwars door het land $(270 \mathrm{~km})$, maar alleen het laatste stuk is geopend voor het passagiersvervoer.

(19) R.J.HARRISON CHURCH, e.., p. 46-48.

(20) C.W.NEWBURY, The Western Slave Coast and its rulers, Oxford, 1961, p. 142.

(21) H.L.VAN DER LAAN, صع. p. 554.

(22) C.COQUERY-VIDROVITCH,o.c, p. 344. 
(23) C.W.NEWBURY, "Historical aspects of manpower and migration in Africa South of the Sahara", L.H. GANN, P. DUIGNAN (eds), Colonialism in Africa, vol. 4., Cambridge, 1975 , p. 523-528.

(24) C.COQUERY-VIDROVITCH, Afrique noire. Permanences et ruptures, Parijs, 1985, p. 324-335 (Les cheminots, aile marchante du syndicalisme africain).

Zie ook de roman van: SEMBENE OUSMANE, Les bouts de bois de Dieu (Bamty mam Yalla). In het Nederlands vertaald als De Houties van God, Amsterdam, 1981.De literaire verwerking van de grote spoorwegstaking van 1947/48 in Frans West-Afrika.

(25) Cfr. M.LINIGER-GOUMAZ, "Transsaharien et transafricain: essai bibliographique", Genève - Afrique vol. 7, nr. 1, 1968, p. 70-84.

Volledig bibliografisch overzicht van de Transsaharaspoorweg: diskussies, lobbywerk en plannen.

(26) F.A.W.BALTZER, Die Kolonialbahnen mit besonderer Berulcksichtigung Afrikas, Berlijn/Leipzig, 1916, 462 p.

(27) Cfr. b.v.: W.BAUMGART,0.ع, 1986, p.25-32 en

D.HEADRICK, The tools of empire: technolegy and European imperialisme in the 19th century New York, 1981, 221 p.

(28) R.J.HARRISON CHURCH, "The evolution of railways in French and British West Africa", Comptes Rendus du Congrès intemational de géographie.Lisbonne.1949 t.4, p.95-114, Lisabon, 1952.

R.J.HARRISON CHURCH, The railways of West Africara geographical and historical analysis. (Ph.D. dissertation,University of London),London, 1943.

R.J.HARRISON CHURCH, "The transport pattern of British West Africa", Geegraphical essays on British tropical lands. London, 1956, p.53-76.

R.J.HARRISON CHURCH, West Africa: a study of the environment and of man's use of it. (Physical,political and economic geography), London, 1960, $547 \mathrm{p}$.

(29) Z.CERVENKA, "The limitations imposed on African land-locked countries", Z.CERVENKA (ed.), Land-locked countries of Africa. (The Scandinavian Insitute of African Studies), Uppsala, 1973, p.17-33.

(30) R.W.CLOMER, G.DALTON, M.HARWITZ en A.A.WALTERS, Growth without development: an economic survey of Liberia Evanston, 1966. (Met o.a. aandacht voor de eerste mijnspoorwegen in Liberia).

(31) P.R.GOULD, The development of the transportation pattern in Ghana, (Part I: The development of transportation before 1964. Ghana's era of the railway; Part II: The present day pattern of commodity flow.The pattems of railway commodity flow, 1955), (Dept. of geography, Northwestern University), Evanston, 1960, X- 164 p. 
(32) G.O.IJEWERE, Rail and road in post-war Nigerian economy, (B.Litt., University of Oxford), Oxford, 1959.

(33) G.LACOGNATA, L'Abidjan - Niger. Etude géographique d'une voie ferré coloniale, (Thèse, Dipl. d'Etudes Sup. de Géographie), Aix-en Provence, 1962.

(34) J.MANGOLTE, "Le chemin de fer de Konakry au Niger, 1890-1914", Revue Erançaise d'Histoire d'Qutre-Mer LV, 1968, p.37- 105.

Belangrijkste historische studie van de Guinée-spoorweg.

(35) OLUFEMI OMOSINI, "Railway projects and Britsh attitude towards the development of West Africa, 1872-1903", Joumal of the Historical Society of Nigeria, vol.V, nr.4, juni 1971, p.491- 507.

J.O. OYEMAKINDE, A history of indigenous labour on the Nigerian railways. 18951945. (Ph.D. thesis, University of Ibadan), Ibadan, 1970.

WALE OYEMAKINDE, "The provident fund on the Nigerian Railway, 1915-1943", Ikenga, 2, 1973, 2, p.32-48.

WALE OYEMAKINDE, "Railway construction and operation in Nigeria, 1895-1911: labour problems and socio-economic impact", Joumal of the Historical Society of Nigeria vol.VII, nr.2, 1974,p.303-325.

Spoorwegplannen van J.Chamberlain: loonarbeid bij de spoorwegen, stimulatie van de marktekonomie.

(36) T.W.ROBERTS, Railway imperialism and Erench advances towards Lake Chad. 18901900. (Ph.D. thesis, University of Cambridge), Cambridge, 1973.

W.BAUMGART, Imperialism. the idea of British and Erench colonial expansion. 18801914. Oxford, 1986, 239 p. (II.6. The technological revolution. The intercontinental railways, p.25- 32).

(37) SALLY HERBERT FRANKEL, Capital investment in Africa: its course and effects, London, 1938, $486 \mathrm{p}$.

"It place special emphasis on mining and railway finance" + bibliografie.

(38) CATHERINE COQUERY-VIDROVITCH, "A propos des investissement français outremer: l'exemple de l'Ouest africain, 1910-1965", in: LEVY-LEBOYER (eds.), La position intemationale de la Erance, p.413-426,Parijs, 1977.

HENRI BRUNSCHWIG, "Politique et économie dans l'empire français d'Afrique noire, 1870-1914", Joumal of African History, XI, 1970, 3, p.401-417.

(39) N.A.COX-GEORGE, Studies in finance and development: the Gold Coast(Ghana) experience 1914-1950, London, 1973. (o.a. financiering spoorwegen).

M. LAKROUM, "Le jeu de l'argent et du pouvoir dans une entreprise coloniale; la Compagnie du Chemin de fer de Dakar à Saint-Louis",Actes du Colloque: Entreprises et entrepreneurs en Afrique (19e et 20e siècles).organisé par le Laboratoire'Connaissance du Tiers Monde', t.II, Parijs, 1983, p.101-122. 
(40) A.G.HOPKINS, e.c, p.194.

(41) PAUL EDWARD PHEFFER, Railroads and aspects of social change in Senegal, 18781933. (Ph.D. dissertation, dept. of History, University of Pennsylvania, 1975), Ann Arbor, Michigan, 1980, XLIX-540p.

(42) SEMI-BI ZAN, Equipement public et changements sociaux en Côte-d'Ivoire.1930-1957. (Thèse d'état, Université de Paris-VII), Parijs, 1981.

SEMI-BI ZAN, "L'infrastructure routière et ferroviaire coloniale.Source de mutations sociales et psychologiques: le cas de la Côte-d'Ivoire(1900-1940)", Afrika Zamani. Revue d'histoire Africaine. Review of African History, dec. 1977, nr.6+7, p.37-52.

(43) A.COCOU, Les travailleurs du chemin de fer au Dahomey sous la colonisation des origines à 1952, (Thése de 3e cycle, Université de Paris-VII), Parijs, 1977.

D.D. CORDELL, J.W. GREGORY, "Labor reservoirs and population: French colonial strategies in Koudougou, Upper Volta, 1914 to 1939", Joumal of African History, 1982, 23, I, p.205-224.

(44) MAMADOU SEYNI MBENGUE, "La grève tragique des cheminots de Thiès", Ethiepiques, revue socialiste de culture négro-afr. 1975, 2, p.63-72. "La grève de Thiès ,sur le réseau Dakar-Niger, 1938, était la première grève ouvrière de masse en AOF".

J.S. SURET-CANALE, "La grève des cheminots africains d'AOF (1947-1948)", Cahiers d'Histoire, nr.28, 1978, p.82-124.

IBA DER THIAM, La grève des cheminots du Sénégal de septembre 1938, 2 vol., (Mémoire de maîtrise, Université de Dakar), Dakar, 1972, 272p.

IBA DER THIAM, "Les origines du mouvement syndical sénégalais. La grève des cheminots du Dakar-Saint-Louis du 13 au 15 avril 1919", Annales de la Faculté des Letures et Sciences humaines de Dakar, 1977, 7, p. 210-239.

AKINTOLA J.G. WYSE, "The 1926 railway strike and Anglo-Krio relations ;an interpretation", Intemational Joumal of African Historical Studies (Boston), 14, 1981, 1, p.93-123. 